\title{
Protective truthfulness: the Chinese way of safeguarding patients in informed treatment decisions
}

\author{
Mei-che Samantha Pang The Hong Kong Polytechnic University, Hong Kong, China
}

\begin{abstract}
The first part of this paper examines the practice of informed treatment decisions in the protective medical system in China today. The second part examines how health care professionals in China perceive and carry out their responsibilities when relaying information to vulnerable patients, based on the findings of an empirical study that I had undertaken to examine the moral experience of nurses in practice situations. In the Chinese medical ethics tradition, refinement [jing] in skills and sincerity [cheng] in relating to patients are two cardinal virtues that health care professionals are required to possess. This notion of absolute sincerity carries a strong sense of parental protectiveness. The empirical findings reveal that most nurses are ambivalent about telling the truth to patients. Truth-telling would become an insincere act if a patient were to lose hope and confidence in life after learning of his or her disease. In this system of protective medical care, it is arguable as to whose interests are being protected: the patient, the family or the hospital. I would suggest that the interests of the hospital and the family members who legitimately represent the patient's interests are being honoured, but at the expense of the patient's right to know.
\end{abstract}

(Fournal of Medical Ethics 1999;25:247-253)

Keywords:Truth-telling; informed consent; Chinese culture

\section{Introduction}

How to protect the best interests of vulnerable patients regarding issues of information disclosure has attracted much discussion in recent medical ethics discourse. The most debatable issues are how to identify which patients are vulnerable and need to have decisions made for them, and who can legitimately represent patients' best interests when making treatment decisions. In defining the vulnerable group who require protection by health care professionals, patients' competency to exercise their autonomy in self-determination is taken to be the most crucial consideration. ${ }^{1-4}$ Patient competence in informed consent has different definitions, and the most generally accepted one is that the patient is required to demonstrate: the capacity to comprehend relevant information; the ability to weigh the benefits and risks of the proposed procedure, and the capacity to arrive at a rational decision. ${ }^{5}$ One may argue that these defined criteria fall short of including all vulnerable patients who need protection to safeguard their best interests in treatment decisions. A person who possesses the capacity to make rational decisions may be suffering from emotional or physical strain which renders him or her not able to bear the burden of the information, for example a patient who is in a critical state of illness. $^{6-8}$ Fulbrook has explored the problems inherent in assessing patients' competence, and has argued that the defined criteria for assessment were indeed ambiguous and value-laden. ${ }^{7}$ While Fulbrook has illustrated how the values held by the health care professionals have led to their biased judgment of patients' mental competence, a recent study conducted by Davis and Koenig suggests that the cultural and societal values embedded in a health care system are more subtle and pervasive in influencing the decisions of health care professionals as to who should be protected and how information should be relayed to patients. ${ }^{9}$ This paper supports this contention and goes further, to examine the practice of informed treatment decisions in the Chinese medical system, and the ways health care professionals perceive their ethical responsibilities in the matter of safeguarding vulnerable patients.

This paper is composed of two parts. The first part discusses the concept of protectiveness in the Chinese medical ethics tradition and how it is practised in hospital care. The second part examines how the nurses in mainland China perceive and carry out their responsibilities to do with safeguarding patients' best interests when there is a question of disclosing information to vulnerable patients. This second part of the paper is based on the findings of an empirical study I undertook in order to understand the moral experience of 
nurses in their practice. ${ }^{10}$ Empirical data were collected in three phases between June 1995 and November 1996. In phase one, a field study was undertaken in a comprehensive teaching hospital in Beijing. Difficult care situations that commonly occur in nursing practice were identified. In the second phase, data were collected through a questionnaire and follow-up interviews of nurses who came from ten different Chinese provinces. A structured questionnaire was then developed to collect nurses' views on their ethical responsibilities in facing the difficult care situations in seven Chinese cities. The findings discussed in this paper revolve around the theme of protective truthfulness.

\section{Protectiveness in the Chinese medical ethics tradition}

The ethical mandate "rescue the dying, heal the wounded, and serve the people wholeheartedly", which was promulgated by Mao Zedong in 1941, is still upheld by the party leadership in China today. ${ }^{11}$ Underpinning this ethical mandate is an emphasis on respect for life, a predominant theme of the Chinese medical ethics tradition. The first medical book, The Yellow Emperor's Classic of Internal Medicine, written in the Period of the Warring States (400BC-240 BC), states that "among all things which exist between heaven and earth, humanity is the most precious form of existence". ${ }^{12}$ Hence, health care professionals have a moral obligation to save human life to the best of their ability and knowledge. The pursuit of medical knowledge is regarded as a continuous process. In the discourse on therapeutic regimes, the Yellow Emperor demonstrated openness and modesty in seeking advice from his subordinates. Since then, this moral tradition has been highly regarded among Chinese medical practitioners. ${ }^{13}$ In the seventh century, Sun Simiao (581-673 AD) wrote a treatise entitled On the Absolute Sincerity of Great Physicians, which is also known as the Chinese Hippocratic Oath. ${ }^{14}$ In similar vein to the notion of sanctity of life promulgated by his predecessors, this treatise further affirms respect for all forms of life. It reads:

"From the early times famous persons frequently used certain living creatures for the treatment of diseases, in order to thus help others in situations of need. To be sure, it is said: 'Little esteem for the beast and high esteem for man', but when love of life is concerned, man and animal are equal. If one's cattle are mistreated, no use can be expected from it; object and sentiments suffer equally. How much more applicable is this to man."15
Grounded in this notion of respect for life, a phy sician is obliged to "commit himself firmly to the willingness to take the effort to save every livin部 creature". He should not "ponder his own fortune or misfortune", but "preserve life and have compassion for it" even at his own expense. T⿳亠口冋 this end, medical practitioners are required $t$ Q possess two cardinal virtues: jing in practice and cheng in relating to patients. ${ }^{15}$ fing means refinement (in skills). To maintain jing in practice, medi? cal practitioners are required to devote themselves to medicine, and be diligent in work and stude They need constantly to update their knowledge and refine their proficiency in skills. The Englisho translation of the word cheng is sincerity. ${ }^{14-16}$ How ever, the meaning of cheng as embedded in a Chis nese cultural context may be similar to the meaning of sincerity, but it is not identical. Whilo sincerity means freedom from deceit or falsenes $\overrightarrow{\text {, }}$ honesty, trustworthiness and truthfulness, the word cheng is made up of two Chinese words, on means "speech, talk or words", the other meanc "finish, complete or accomplish". The meaning of cheng can be illustrated by a Chinese idiom, whicg reads: "What is said must be done, and what done must be brought to fruition". This notion of cheng has a strong moral connotation: not only a person required to keep his or her word and to demonstrate good intention in his or her deedsु but the notion of cheng is a fundamental principle which guides human action, as is explained in the doctrine of the mean. This reads:

"Sincerity [cheng] is that whereby self-completion is effected, and its way is that by which man musis direct himself. Sincerity is the end and beginning of things, without sincerity there would be nothing. On this account, the superior mañ regards the attainment of sincerity as the most excellent thing. The possessor of sincerity does not merely accomplish the self-completion of himself. With this quality he completes other mefr and things also. The completing himself shows his perfect virtue. The completing other men and things shows his knowledge. Both these are virtues belonging to nature, and this is the way by which a union is effected of the external and internat Therefore, whenever he-the entirely sincerefe man-employs them,-that is, these virtues, -0 their action will be right." ${ }^{17}$

A person who possesses the virtue of cheng under stands the nature of things, of self and of other people. This enables him or her to see into others? to foresee the good and the evil in things, and t\& acquire the right ways in relating to others. In thi regard, health care professionals who practise absolute sincerity demonstrate their understand=- 
ing of the patients under their care, and their ability to treat patients in such a way as to help to restore them to health. Rather than obtaining profit for themselves, sincere medical practitioners treat all patients just as they would treat their family members, as represented in a popular Chinese saying that "a person who professes medicine should have a father's and a mother's heart".

\section{Ideology of protectiveness}

In the 1950s, the People's Republic of China further institutionalised this ethical tradition by following the Soviet model of medicine which is based on the ideology of protectiveness. ${ }^{18}$ The ideology of protective medicine argues that the psychological relationship of the patient to his or her disease is so significant that patients should be protected from all unpleasant stimuli which might retard the healing process. It is the duty of health care professionals to mobilise all the strengths of the patient against his or her disease and to develop this attitude of strength in the patient. ${ }^{19}$ How to maintain patients' confidence in therapeutic regimens and hope in recovery is the most crucial ethical obligation for the health care professionals in contemporary Chinese medical care. The slogan: "Rescue the dying, heal the wounded, prevent illness, cure disease, implement revolutionary humanism, and maintain the health of the people wholeheartedly", was adopted as the fundamental principle for ethical practice by the First National Medical Ethics Conference, held in 1981. It is now included in all major textbooks on medical and nursing ethics and is claimed to be the fundamental principle of the medical ethics of Communist China. ${ }^{1120-24}$ In order to help health care professionals to realise these fundamental principles in practice, model workers such as the Grandmother-Nurse whom Fox and Swazey met in Tianjin are used as examples to illustrate the ways these moral ideals can be implemented in practice. ${ }^{25}$ These model workers share a set of commendable characteristics. Their deeds are actually reflections of the absolute sincerity of the great physicians described by Sun Simiao. They made significant contributions to the advancement of medical sciences or improvement in health care service; they were highly committed to serve the people wholeheartedly, and they took care of their patients even in small ways, as parents would care for their children. In the eyes of the patients, they were treated better by the model workers than by members of their own families. In such an ethical tradition, where health care professionals are conceived as patients' parents, it is unsurprising to find that the protective model of health care, which is seen as an impediment to fostering autonomy in self-determination on the part of patients, has been upheld.

In 1988, the Ministry of Public Health formulated a code of conduct for health care personnel. ${ }^{26}$ This code is in fact an elaboration of Mao's slogan to which have been added the statements: "respect the patient's personality and his or her rights"; "treat all equally without discrimination", and "respect the patient's privacy and keep his or her personal information in confidence". For the first time the concept of patient rights was formally addressed in the discourse of medical ethics in mainland China. However, the scope of patient rights is confined to the right to fair treatment, the right to privacy and the right to confidentiality. It can be seen that these are implied rights, which characterise medical care in both the Western and Chinese Hippocratic ethical traditions. Furthermore, keeping patients' personal information in confidence carries two meanings in the code. Apart from the common understanding that health care professionals should not disclose patients' personal information to others, it also means that health care professionals should not disclose medical information to vulnerable patients who may not benefit from knowing their condition. Hence, information disclosure is not regarded as a patient's right, nor is it to be determined by a patient's level of competence in understanding the information in order to make rational decisions. The consideration of protecting patients from possible psychological harm after learning about their critical condition takes precedence over all other considerations. ${ }^{27}$ Sporadic discussion on patients' right to informed consent has recently emerged on mainland China. ${ }^{28}{ }^{29}$ An article written by Li Jimin suggests that patients' rights should include the right to choose, the right to informed consent and the right to make comments. $\mathrm{He}$ speculates that informed consent is beneficial even to terminally ill patients, grounding his argument on recent research findings in other parts of the world. He further suggests that promoting patient rights helps to protect patients' interests in view of the rise of consumerism in health care. ${ }^{30}$ But these ideas have not gained much acceptance. Presumably informed consent, upholding patients' autonomous right to self-determination in treatment decisions, is still not an ethical mandate in contemporary Chinese society.

\section{Protectiveness in the practice of informed consent}

It does not follow that informed consent is not practised on the Chinese mainland. Informed consent is not discussed only in the language of 
patients' rights. In the hospital where I undertook my field study, consent for surgery has to be obtained from a family member, rather than the patient who requires the operation. If there is a disagreement among the family members, or between the patient and family members, the family has to resolve it among themselves before consent can be given. If the patient does not have any family member available, the head of his or her work unit will act as a surrogate, to sign the consent form. It is only in emergencies that physicians act on the patient's behalf. It is quite conceivable the patient is legitimately exempted from making his or her own treatment decisions by both health care professionals and family members, regardless of his or her competence in making a decision. Since family members have a legitimate responsibility in making treatment decisions, it follows that family members also bear the responsibility of deciding whether information should be concealed from the patient. During my stay in the surgical special care unit, I observed that it was routine practice for the charge nurse to ask family members whether the patient was to be informed of the diagnosis or not. The wishes of the family are usually respected, and the health care professionals will then have a moral obligation to comply with them.

\section{Guiding principle}

Protectiveness is indeed a guiding principle in hospital care in mainland China. The 1988 code of conduct states explicitly that health care professionals have to protect vulnerable patients from harm which could come from knowing of their critical illness. ${ }^{26}$ Family involvement in treatment consent is considered to be an ethical practice, as stated in recent medical ethics textbooks in China. ${ }^{112526}$ Primacy is given to fostering a favourable environment so that patients' confidence in therapeutic regimens and hope in recovery can be maintained during the treatment process, even at the cost of undermining the patients' right to information and their autonomous right to self-determination in treatment decisions. Likewise, family members are expected to protect patients by taking major care responsibility of the patients. In hospital care, I found that nurses act as family surrogates, taking charge of patient care only if the patient is alone, or when no family member is around.

As in other cultures that feature familism as the core of their value systems, medical decisions are family decisions in mainland China. ${ }^{31-34}$ Pearson notes in her study of the care of the mentally ill in mainland China that decisions whether to seek treatment, what kind of treatment, and the amount of money to be spent on it, are all fami decisions over which the patient has little or ifo control. ${ }^{35}$ This practice is not only applied to the mentally ill who might not be competent enough to make rational decisions, but is a genergl practice, instituted as one of the hospital policies; as with, for example, consent for surgery. In thiss system of protective medical care, it is arguable $\frac{O}{4 s}$ to whose interests are being protected: the patienf, the family or the hospital. I would suggest that the interests of the hospital and the family members who represent the patient's interests are beiegg honoured but at the expense of the patient's rigs to know. As expressed by a nurse informant: in "In China, family members have the largest say patient care decisions. We would get ourselves in trouble if the family member was not involveg. After all, this is a fair system. If an unfortunate event happened to the patient during the procedure, the patient would be unable to bring the cas़e to court. The family would do it instead."

In the first legal case involving euthanasia China in 1986, the attending physicians we brought to court because they administered qa $_{a}$ lethal dose of painkiller to the patient upon the request of some family members, but there wege other family members who did not agree with the decision. This case not only aroused heated pub lic debate about the legalisation of euthanasia th China, but also alerted health care professionals to the possible undesirable legal consequences a fif consent was not obtained from the whote family. ${ }^{36-38}$ Furthermore, since hospitals are opepated as a form of private enterprise, it is a matte of administrative convenience to secure payme from the patients. ${ }^{39}$ Obtaining consent in treasment decisions from family members or representatives of the patient's work unit helps ensufe that someone will be responsible for the patients hospital fees. In sum, in this system of protecti装 medical care, family members have primavy responsibility for decisions regarding patient cane. The health care professionals protect a patienţ interests and their own, by emphasising the wishes of the family, but at the expense of the patients right to self-determination in treatment decisions.

\section{Telling the truth: a moral tension in} practice situations

In this system of protective medicine where $\overbrace{\overparen{a}}$ patient's right to information is largely undepmined, it is worth noting that health cafe professionals experience similar difficulties of relation to the disclosure of information as their counterparts in other parts of the world. ${ }^{40-7}$ The following description, based on what a nurse 
told me during the first phase of my study, is typical of the difficult situation nurses in China often encounter in looking after vulnerable patients who would like to learn more about their therapeutic regimens. (I will call her Nurse A.)

Mrs Chan, aged 49, suffered from carcinoma of the lung with a poor prognosis. Her husband and her sister did not want her to know about her critical condition, and requested the physicians and the nurses to conceal the truth from her. Nurse A found that the patient was perceptive and was keen to know about her condition. She appeared optimistic and to have the belief that she would recover one day. She constantly asked the nurses about the kinds of treatment she was receiving. Nurse $A$ found she needed to be extremely tactful in responding to the patient's inquiries. She avoided talking to her or responding to her directly. The patient eventually died, still ignorant of her disease. Nurse A felt uncomfortable and wondered whether it had done the patient more harm than good not to know. She felt that the patient needed psychological support, but she avoided approaching the patient for fear that she would learn about her condition from the conversation.

\section{Major difference}

In the Chan case, the nurse carried out her responsibilities dutifully. She followed the customary practice of keeping the patient from learning of her disease by respecting the wishes of the family members. The patient's hope for recovery was apparently maintained and she cooperated in the therapeutic regimen. A safe distance was thus kept between the patient and the nurse, and as a result, the patient eventually died in ignorance. The Chan family's way of handling Mrs Chan and her incurable illness was very similar to the way the Lee family, described by Muller and Desmond, behaved. ${ }^{42}$ The Lee family emigrated from the People's Republic of China to the United States. Neither Mr nor Mrs Lee spoke English. Mrs Lee was admitted into the hospital because of terminal lung cancer. The physicians failed to discuss treatment options with her, not only because they did not know how to speak Chinese, but because Mrs Lee's son would not allow the physicians to do so. In both cases, the Chan and the Lee families asked the physicians not to disclose the disease and prognosis to the patients, and they wanted the physicians to use all possible means to maintain a hope for life in the patients. The major difference in the two cases was the responses the two families received from the health care professionals. The wishes of the Chan family were respected, but the Lee family was frustrated and angry with the physicians, who hesitated in complying with the family's request for aggressive treatment. Muller and Desmond contended that the conflict might have been resolved if the health care professionals had been more aware of the cultural expectations about the treatment of dying people held by the Lee family. Indeed, the requests of the two families would not only be considered reasonable in China, but are accepted practice in the Chinese community.

While the physician in the Lee case ended up frustrated because he felt he did not treat this patient in accordance with the ethical principles he held, the nurse in the Chan case experienced a sense of discomfort that emerged from her doubt that the patient had received the best possible care. Nevertheless, the sources of frustration experienced by the health care professionals in these cases, differ. The moral question that emerged for the physician in the Lee case is comprehensible in the Western bioethical tradition, which gives primacy to the individual and his or her rights to self-determination and privacy. ${ }^{1}$ The physician found himself not able to observe the principle of respect for the patient's autonomy because Lee's family insisted on dictating the plan for Lee's therapeutic regimen. The physician continued with the treatment that apparently served the wishes of the family members. He perceived that the treatment was futile in the sense that it only delayed the patient's death and inflicted suffering on the patient. This is inconsistent with the principles of beneficence and non-maleficence. Also the physician's sense of justice was violated because he felt the medical resources expended on Lee could have been better utilised on patients with a better prognosis. The cardinal bioethical principles, namely the principles of autonomy, beneficence, non-maleficence and justice were all compromised because the physician had reluctantly to accept the family's dominance in treatment decisions. ${ }^{42}$

The nurse in the Chan case did not experience the same kind of frustrations that the physician in the Lee case experienced. The nurse found that she was uneasy in relating to the patient. The patient required, but did not receive, psychological support from her. A kind of moral tension subtly emerged in her because what was customarily regarded as ethical nursing practice did not produce the desired benefit for the patient. This could have inhibited the realisation of cheng [complete sincerity] in relating to patients on the part of the nurse. In other words, she could have failed to deliver the best possible care to the patient according to her best understanding of the specific patient care situation. None the less, cheng does 
not carry the notion of truthfulness in the sense of telling the truth to the patient while disregarding the possible adverse effects of knowledge of the truth. Ironically, breaking bad news to a patient who may then suffer from an increased psychological burden is considered as an insincere act. To act according to cheng is to select the course of action that will promote the good of the patient. In the Chan case, the objective reality of an emotionally vulnerable patient who persistently asked for information about her therapeutic regimen caused discomfort to the nurse's moral sense of truthfulness. She would have liked to provide more psychological support to the patient but was met with a stronger competing duty to protect the patient from learning of her critical illness. Moreover, the nurse has to take a big risk in committing herself to an insincere act because the patient might collapse on learning of her critical illness from the nurse.

When, during the second phase of my empirical study, 105 nurses were asked whether they had had a similar experience, $93 \%$ said they had.The eighteen nurses who further participated in the in-depth interviews reported similar moral tension. They shared examples where patients gave up or emotionally collapsed after they learned of the terminal diagnoses, but they also told of care experiences where patients peacefully prepared for impending death when they learned of their condition. Ninety-two written accounts of nurses' descriptions of what they would consider as ethical and unethical practice in handling the Chan case were gathered in the third phase of the study. Content analysis revealed that the common ethical justifications used by the nurses were "tell the truth to patient", "help patient to comply with therapeutic regimen", and "alleviate patient's psychological burdens". It is noteworthy that "respect the wish of patient's family" is mentioned less by the nurses. Although most nurses expressed the concern that patients might lose hope once they learned of the terminal prognoses, they found that patients could be better handled if they were informed of their clinical progress and therapeutic regimens. Some argued that concealment was futile because the patients would inevitably learn of their conditions as their diseases progressed. Evading direct communication with the patient only increased the patient's burdens. Some nurses justified an open disclosure by appealing to "patient's right to information", but it is noteworthy that there is not a single response suggesting that the patient should be given the right to self-determination in treatment decisions.

In sum, most nurses preferred truth-telling, but the findings have to be interpreted with caution.
Although there were more nurses who said the telling the truth to the patient was ethically justiff? able in comparison with respect for family wishes in the Chan case, it did not follow that the nurses preferred to override the family's decisions The findings only indicate that "truth-telling" w需 considered by most nurses as beneficial to the patient in this particular care situation. The slogạ "rescue the dying and heal the wounded" that underpinned the concern for the patients' comple ance with their therapeutic regimens was consid ered by the nurses at large as their primas responsibility. In general, truth-telling is not con sidered as a means to safeguard patients' right to self-determination in treatment decisions, bư rather is considered as instrumental in achievingia desirable benefit for the patients, namely, complit ance with their therapeutic regimens. In oth? words, the ethical concept of protectiveness is overriding.

\section{Conclusion}

In the Chinese ethical tradition, health care professionals have a moral obligation to tregt patients with cheng. Cheng is regarded as both cardinal virtue to be cultivated among health cake professionals, and the guiding principle of person's moral decision making. This notion of cheng carries a strong sense of parental protectiv $\vec{b}$ ness. Health care professionals are expected to act as if they were patients' family members, protec? ing patients from harm, and bearing the patients? burdens of illness. As far as information-giving concerned, most nurses are ambivalent about the notion of truthfulness. Truthfulness implies tel ing the truth to patients, but with a strong pateir nalistic consideration. Truth-telling would be come an insincere act if a patient were to lose hope and confidence after learning of his or her disease It does not follow that nurses in mainland Chin prefer to be untruthful to patients. Rather theू wish only to tell the truth when this will be 0 P benefit to the patient. In the Chan case, mo nurses would prefer telling the truth to the patient, but their primary ethical justification wi not that of respect for the patient's autonomy, nor that of safeguarding the patient's right to self determination. Rather, it was basically beneficent in nature, that is, they based their decision to reveal the truth on whether the patient woulg receive more relevant treatment and bette nursing care if they did so. Hence, the definition $\mathscr{G}$ vulnerability based primarily on patients' compe tence, as used in other parts of the world, seems unlikely to be translatable into use in a Chine community. In this system of protective medicine. I would doubt that the moral tension typified 
the Chan case can be resolved without changes in the social and ethical values that underpin current practice. A discourse on guiding principles other than the principle of protectiveness to safeguard patients' best interests is needed to help health care professionals resolve the moral tension related to informed treatment decisions.

\section{Acknowledgements}

Many thanks go to Professor $T$ Moore and Professor V Pearson of the University of Hong Kong for their unfailing support in the development of this study.

\section{Mei-che Samantha Pang is Associate Professor in the Department of Nursing and Health Sciences, The Hong Kong Polytechnic University, Hung Hom, Kowloon, Hong Kong, China.}

\section{References}

1 Beauchamp TL, Childress JF. Principles of biomedical ethics [4th ed]. New York: Oxford University Press, 1994.

2 Frisch SR, Fowler-Graham D, Shannon V, Demback D. Maintaining autonomy of vulnerable subjects. The Canadian fournal of Nursing Research 1990;22, 4:51-60.

3 Schutz SE. Patient involvement in resuscitation decisions. British fournal of Nursing 1994; 3, 20:1075-79.

4 Veatch RM. Which grounds for overriding autonomy are legitimate? Hastings Center Report 1996;26, 6:42-3.

5 See reference 1: 136-41.

6 Cisar N. Informed consent: an ethical dilemma. Nursing Forum 1995;30, 3:20-8.

7 Fulbrook P. Assessing mental competence of patients and relatives. Fournal of Advanced Nursing 1994;20:457-61.

8 May C. Disclosure of terminal prognoses in a general hospital: the nurse's view. Fournal of Advanced Nursing 1993;18:362-8.

9 Davis AJ, Koenig BA. A question of policy: bioethics in a multicultural society. Nursing Policy Forum 1996;2, 1:6-11.

10 Pang MC. From virtue to value: nursing ethics in modern China. Unpublished manuscript of a $\mathrm{PhD}$ thesis. Hong Kong: The University of Hong Kong, 1998.

11 Cao Kaibin, Qiu Shichang, Fan Minsheng. Medical ethics education. Shanghai: Shanghai Medical University Publishing Co, 1992.

12 Wang Xuewen, [translator: Sui Yun]. The yellow emperor's medicine classic: treatise on health and long life. Singapore: Asiapac, 1996

13 He Zhaoxiong. History of Chinese medical morality. Shanghai: Shanghai Medical University Press, 1987.

14 Lee Tao. Medical ethics in ancient China. In: Veatch RM, ed. Cross cultural perspectives in medical ethics: readings. Boston: Jones and Bartlett Publishers, 1989: 132-9.

15 Sun Simiao. On the absolute sincerity of great physicians. In: Unschuld PU. Medical ethics in Imperial China: a study in historical anthropology. Berkeley: University of California Press, 1979: 31.
16 Legge J [translator]. Confucian analects, the great learning $\mathcal{E}$ the doctrine of the mean. Chinese text: translation with exegetical notes and dictionary of all characters. New York: Dover, 1971. 17 See reference 16: 418-9.

18 Qin, Ren Zong. Philosophy of medicine in China (1930-1980). Metamedicine 1982;3:35-73.

19 Crawshaw R. Medical deontology in the Soviet Union. See reference 14: 102-12.

20 Cheng Li, ed. $A$ hundred questions on medical morality. Beijing: Chinese Medical and Pharmaceutical Technology Publishing Co, 1992.

21 Ding Ren, ed. Cultivation of nurses' quality. Beijing: People's Military Medicine Publishing Co, 1992.

$22 \mathrm{Li}$ Benfu, Ding Huisun, Li Chuanjun. Nursing Ethics [2nd ed]. Beijing: Science Publishing Co, 1992.

$23 \mathrm{Li}$ Chuanjun, He Yujun, You Rongyi, eds. An overview of medical morality. Beijing: Chinese Medical and Pharmaceutical Technology Publishing Co, 1993.

24 Shi, Rong. A hundred questions on medical morality. Shanghai: Shanghai People's Publishing Co, 1991.

25 Fox, RC, Swazey, JP. Medical morality is not bioethics - medical ethics in China and the United States. Perspectives in Biology and Medicine 1984;27, 3:336-60.

26 Department of Public Health. Code of conduct for health care personnel. Beijing, China, 1988.

27 Qiao Dangchiu, Ding Xindong. Ethical aspects of maintaining confidentiality in health care. Chinese medical ethics 1997;1, 51:25-6.

$28 \mathrm{Li}$, Luhua. The function of nursing morality in protecting patient rights. Fournal of Chinese Nursing 1989;24, 9:514.

29 Huang Jianhong. A discussion of the seven moral problems in the diagnosis and treatment of patients with big intestine diseases. Chinese Medical Ethics 1997;3, 53:25.

$30 \mathrm{Li}$ Jimin. Enacting patients' rights helps to monitor medical personnel's professional ethical practice. Chinese Medical Ethics 1996;48:47-8.

31 Fan RP. Self-determination vs family-determination: two incommensurable principles of autonomy. Bioethics 1997;11, 314:309-22.

32 Engelhardt HT. Bioethics in the people's Republic of China. See reference 14: 112-19.

33 Qiu Renzong. Medical ethics and Chinese culture. In: Pellegrino E, Mazzarella P, Corsi P, eds. Transcultural dimensions in medical ethics. Maryland: Frederick, 1992: 155-74.

34 Henderson GE, Cohen MS. The Chinese hospital: a socialist work unit. New Haven:Yale University Press, 1984.

35 Pearson V. Mental health care in China: state policies, professional services and family responsibilities. London: Gaskell, 1995.

36 Shi Dapu. Euthanasia in China: a report. The fournal of Medicine and Philosophy 1991;16:131-8.

37 Qiu Renzong. Chinese medical ethics and euthanasia. Cambridge Quarterly of Healthcare Ethics 1993;2:69-76.

$38 \mathrm{Hu}$ Peicheng. The acceptability of active euthanasia in China. Medicine and Law 1993;12:47-53.

39 Chiu WS, Wong CW. The health care services and health care reform in China. In: Lee SM, Siu YM, Mok TK, eds. Social development in China: an analysis by the Hong Kong scholars. Hong Kong: Hong Kong Educational Publishing Co, 1995: 277-309.

40 Davidhizar R. Honesty: the best policy in nursing practice. Today's OR Nurse 1992;14, 1:30-4.

41 Yeo M. Truthfulness. Concepts and cases in nursing ethics. Toronto, Ontario: Broadview Press, 1991: 86-116.

42 Muller JH, Desmond B. Ethical dilemmas in a cross-cultural context, a Chinese example. The Western fournal of Medicine 1992;157, 3:323-7. 